\title{
Opioid endocrinopathy: A clinical problem in patients with cancer pain
}

\author{
ALPARSLAN MERDIN ${ }^{1}$, FATMA AVCI MERDIN $^{1}$, ŞEYDA GÜNDÜZ $^{2}$, \\ HAKAN BOZCUK ${ }^{3}$ and HASAN ŞENOL COŞKUN ${ }^{3}$ \\ ${ }^{1}$ Department of Internal Medicine, Akdeniz University Hospital, Antalya 07058; \\ ${ }^{2}$ Department of Medical Oncology, Antalya Education and Research Hospital, Antalya 07070; \\ ${ }^{3}$ Department of Internal Medicine, Division of Oncology, Akdeniz University Hospital, Antalya 07058, Turkey
}

Received December 6, 2014; Accepted November 25, 2015

DOI: $10.3892 /$ etm.2016.3156

\begin{abstract}
Opioids are commonly used in cancer pain management. The present study aimed to investigate the occurrence of endocrine dysfunction in patients with cancer pain treated with opioids. The study included 20 patients with cancer-associated pain. All data were obtained from malignant tumors diagnosed and followed up at the Oncology Clinic of Akdeniz University Hospital (Akdeniz, Turkey) between May 2009 and December 2013. Serum samples were collected to determine the levels of hypophyseal, gonadal and thyroid hormones. The inclusion criteria for the study were as follows: Chronic cancer pain, daily treatment with a morphine equivalent daily dose (MEDD) of $\geq 25 \mathrm{mg} / \mathrm{dl}$ for $\geq 1$ month, and a visual analog score of $<2$. All independent predictors were evaluated using logistic regression analysis. The results did not demonstrate any significant association between MEDD and gender, or the levels of adrenocorticotropic hormone, cortisol, prolactin, thyroid-stimulating hormone, free thyroxine, follicle-stimulating hormone and luteinizing hormone. However, the levels of testosterone $(\mathrm{P}=0.040)$ and of free testosterone $(\mathrm{P}=0.041)$ were significantly affected by the MEDD. Conversely, prolactin levels were demonstrated to significantly increase with MEDD $(\mathrm{P}=0.083)$. The results also indicated that the required opioid analgesic dose and MEDD were significantly affected by age $(\mathrm{P} \leq 0.001)$. Opioid therapy in patients with cancer may inhibit gonadal function and cause hyperprolactinemia.
\end{abstract}

Correspondence to: Dr Seyda Gündüz, Department of Medical Oncology, Antalya Education and Research Hospital, Kazım Karabekir Street, Soguksu, Antalya 07070, Turkey

E-mail: drsgunduz@gmail.com

Key words: opioid treatment, endocrinopathy, hypogonadism, hyperprolactinemia, malignancy-associated pain, cancer, adrenal insufficiency, age

\section{Introduction}

Chronic malignant pain is often managed using opioid medication. However, opioid-associated adverse effects have also increased with the widespread usage of opioids. Constipation, sedation, nausea, vomiting, respiratory depression, and physical dependence are some of the most well-established side-effects of opioid treatment.

Previous studies have demonstrated that opioids alter endocrine function $(1,2)$. Opioid-induced endocrinopathy is a common consequence of prolonged opioid therapy, yet is infrequently diagnosed (3). Opioids have been reported to decrease the levels of gonadal sex hormones, growth hormones, cortisol and dehydroepiandrosterone sulfate $(4,5)$. Opioids are known to exert detrimental effects on the endocrine system, including the hypothalamic-pituitary-adrenal (HPA) axis $(6,4)$. The mechanisms underlying this interference are unknown, but it has been hypothesized that opioids inhibit the HPA axis via the $\mu$-opioid receptor (7). Endogenous and exogenous opioids also exert an inhibitory effect on gonadotropin-releasing hormone (3).

The preclinical study conducted by Adams et al (8) demonstrated that opioids decrease testosterone secretion. The present study aimed to investigate the occurrence of endocrine dysfunction in patients with cancer pain treated with opioids.

\section{Materials and methods}

Data collection and study design. The study included 20 patients with cancer-associated pain. All data were obtained from patients with malignant tumors who were diagnosed and followed up at the Oncology Clinic of Akdeniz University Hospital (Antalya, Turkey) between May 2009 and December 2013. The study was designed to be a retrospective study. Serum samples had been measured to determine the levels of free testosterone and total testosterone (predominantly in men), the levels of follicle-stimulating hormone (FSH), luteinizing hormone (LH), and estradiol (predominantly in women), as well as the levels of growth hormone (GH), serum free thyroxine (fT4), thyroid-stimulating hormone (TSH), prolactin, adrenocorticotropic hormone (ACTH) and serum cortisol. The blood samples were taken at 8:00 a.m. Patients 
with a history of cranial radiation, cranial surgery, pituitary tumors, adrenal metastasis, brain metastasis, anxiety, major depressive disorder, alcoholism, acute or chronic infection, cachexia, obesity, uncontrolled pain management or hormone replacement therapy were excluded from the present study, due to the fact that these conditions may affect the HPA axis or endocrine system. In addition, patients that were receiving medication that may interfere with pituitary function or the endocrine system, such as megestrol acetate, continuous steroid usage for three weeks, tamoxifen, anastrozole, metoclopramide or psychiatric drugs were not included in the study. The inclusion criteria were chronic cancer-associated pain, and daily treatment with a morphine equivalent daily dose (MEDD) $\geq 25 \mathrm{mg} / \mathrm{dl}$ for $\geq 1$ month. None of the patients in the current study were $>80$ years old.

Pain was measured using the visual analog score (VAS). All patients had a VAS of $<2$, which indicated mild to no pain. Obesity was classified according to body mass index (BMI). Patients with a BMI of $>30$ were not included in the study. In addition, patients with an Eastern Cooperative Oncology Group score of $>2$ were also not included in the study. The levels of procalcitonin and C-reactive peptide were used to exclude patients with infections. Daily opioid use was recorded, and MEDD was calculated using the equianalgesic conversion table listed in the study conducted by Cepeda et al (9).

Statistical analysis. The data were presented as means \pm standard deviations for normally distributed variables. The variables were investigated using visual (histograms and probability plots) and analytical methods (Kolmogorov-Simirnov and Shapiro-Wilk's tests), in order to determine whether the data were normally distributed (including MEDD scores, and levels of ACTH, cortisol, prolactin, TSH, fT4, FSH, LH, testosterone and free testosterone). Independent predictors were examined using logistic regression analysis. Statistical analyses were performed using SPSS software, version 20.0 (IBM SPSS, Armonk, NY, USA). $\mathrm{P}<0.05$ was considered to indicate a statistically significant result.

\section{Results}

The present study evaluated the data of 20 patients with cancer who were diagnosed and followed-up at the Akdeniz University Hospital between May 2009 and December 2013. All patients received opioid treatment for $\geq 1$ month for pain management.

The median follow-up period was 9.4 months. The median age of the patients was 50 years (range, 24-72 years). Of the patients, $65 \%$ were male and $35 \%$ were female. A total of 15 patients $(75 \%)$ had metastatic cancer. The demographic data of the patients are summarized in Table I.

Serum TSH levels (normal range, 0.2-4.2 $\mu \mathrm{IU} / \mathrm{ml}$ ) were $>4.2 \mu \mathrm{IU} / \mathrm{ml}$ in $20 \%$ of the patients, and $<0.2 \mu \mathrm{IU} / \mathrm{ml}$ in $5 \%$ of the patients (Table II). Serum fT4 levels (normal range, $0.9-1.7 \mathrm{pg} / \mathrm{ml}$ ) were $<0.9 \mathrm{pg} / \mathrm{ml}$ in $5.2 \%$ of patients, and none of the patients exhibited serum fT4 levels higher than the upper limit of the normal range ( $>1.7 \mathrm{pg} / \mathrm{ml}$; Table II). Serum cortisol concentrations (normal range, 4.3-22.4 $\mu \mathrm{g} / \mathrm{dl}$ ) were lower than the normal range in $15 \%$ of patients and higher than the normal
Table I. Characteristics of the patients $(\mathrm{n}=20)$.

\begin{tabular}{lc}
\hline Characteristic & Value \\
\hline Gender, $\mathrm{n}(\%)$ & \\
Female & $7(35)$ \\
Male & $13(65)$ \\
Age, years & \\
Median & 50 \\
Range & $24-72$ \\
Metastases location, $\mathrm{n}(\%)$ & \\
None & $5(25)$ \\
Visceral & $10(50)$ \\
Bone & $3(15)$ \\
Bone and visceral & $2(10)$ \\
ECOG score, $\mathrm{n}(\%)$ & \\
0 & $10(50)$ \\
1 & $8(40)$ \\
2 & $2(10)$ \\
\hline
\end{tabular}

ECOG, Eastern Cooperative Oncology Group.

range in $40 \%$ of patients (Table II). Serum total testosterone levels (male normal range, 1.9-5.4 ng/ml; female normal range, $0.06-0.8 \mathrm{ng} / \mathrm{ml}$ ) were lower than the normal range in $68.7 \%$ of patients, and serum free testosterone levels (male normal range, $4.9-21.6 \mathrm{pg} / \mathrm{ml}$; female normal range, $0-2.6 \mathrm{pg} / \mathrm{ml}$ ) were lower than the normal range in $57.1 \%$ of patients (Table II). Serum FSH levels (male normal range, 1.5-12.4 mIU/ml; female normal range, $3.5-12.5 \mathrm{mIU} / \mathrm{ml}$ ) were lower than the normal range in $30 \%$ of patients, and higher in $45 \%$ of patients. Serum LH levels (male normal range, 1.7-8.6 mIU/ml; female, 2.4-12.6 $\mathrm{mIU} / \mathrm{ml}$ ) were lower than the normal range in $30 \%$ of patients and higher in $40 \%$ of patients. Serum $\mathrm{GH}$ concentrations were within the normal range $(0-8 \mathrm{ng} / \mathrm{ml})$ in $94.8 \%$ of patients. Serum prolactin concentrations (normal range, $4.1-18.4 \mathrm{ng} / \mathrm{ml}$ ) were above normal values in $42.9 \%$ of patients, but none of the patients had concentrations below the normal range (Table II). Serum ACTH concentrations (normal range, $0-65 \mathrm{pg} / \mathrm{ml}$ ) were within the normal range in $94.5 \%$ of patients (Table II). Lastly serum estradiol levels (normal range, $24-195 \mathrm{pg} / \mathrm{ml}$ ) were lower in $25 \%$ of patients and higher in $12.5 \%$ of patients (Table II).

The median MEDD of the patients was 180 (range, 10-420). Independent predictors of the MEDD were evaluated using logistic regression analysis, but no significant association was found between MEDD and gender, or the levels of ACTH, cortisol, prolactin, TSH, fT4, FSH or LH. However, the levels of testosterone $(\mathrm{P}=0.040)$ and the levels of free testosterone $(\mathrm{P}=0.041)$ were significantly affected by MEDD (Fig. 1). These results indicate that as the MEDD increases the testosterone and free testosterone levels decrease (Fig. 1). Conversely, prolactin levels were determined to increase as the MEDD increases $(\mathrm{P}=0.083)$. Lastly, MEDD was found to be significantly affected by age $(\mathrm{P} \leq 0.001)$, indicating that the required dose of opioid analgesic is affected by age (Fig. 2). 
Table II. Hormonal status of the patients.

\begin{tabular}{|c|c|c|c|c|}
\hline \multirow[b]{2}{*}{ Hormone } & \multirow[b]{2}{*}{ Normal range } & \multicolumn{3}{|c|}{ Hormone levels of patients, $\mathrm{n}(\%)$} \\
\hline & & Lower & Normal & Higher \\
\hline $\mathrm{TSH}(\mathrm{n}=20), \mu \mathrm{IU} / \mathrm{ml}$ & $0.2-4.2$ & $1(5)$ & $15(75)$ & $4(20)$ \\
\hline fT4 $(\mathrm{n}=19), \mathrm{pg} / \mathrm{ml}$ & $0.9-1.7$ & $1(5.2)$ & $18(94.8)$ & $0(0)$ \\
\hline ACTH $(\mathrm{n}=18), \mathrm{pg} / \mathrm{ml}$ & $0-65$ & $1(5.5)$ & $17(94.5)$ & $0(0)$ \\
\hline Cortisol $(\mathrm{n}=20), \mu \mathrm{g} / \mathrm{dl}$ & $4.3-22.4$ & $3(15)$ & $9(45)$ & $8(40)$ \\
\hline FSH $(n=20), \mathrm{mIU} / \mathrm{ml}$ & $\begin{array}{r}\text { Female: } 3.5-12.5 \\
\text { Male: } 1.5-12.4\end{array}$ & $6(30)$ & $5(25)$ & $9(45)$ \\
\hline $\mathrm{LH}(\mathrm{n}=20), \mathrm{mIU} / \mathrm{ml}$ & $\begin{array}{c}\text { Female: } 2.4-12.6 \\
\text { Male: } 1.7-8.6\end{array}$ & $6(30)$ & $6(30)$ & $8(40)$ \\
\hline Total testosterone $(\mathrm{n}=16), \mathrm{ng} / \mathrm{ml}$ & $\begin{array}{c}\text { Male: } 1.9-5.4 \\
\text { Female: } 0.06-0.8\end{array}$ & $11(68.7)$ & $5(31.3)$ & $0(0)$ \\
\hline Free testosterone $(\mathrm{n}=14), \mathrm{pg} / \mathrm{ml}$ & $\begin{array}{l}\text { Male: } 4.9-21.6 \\
\text { Female: } 0-2.6\end{array}$ & $8(57.1)$ & $6(42.9)$ & $0(0)$ \\
\hline $\mathrm{GH}(\mathrm{n}=19), \mathrm{ng} / \mathrm{ml}$ & $0-8$ & $0(0)$ & $18(94.8)$ & $1(5.2)$ \\
\hline Estradiol $(\mathrm{n}=8), \mathrm{pg} / \mathrm{ml}$ & $\begin{array}{l}\text { Female: } 24-195 \\
\quad \text { Male: } 13.5-59.5\end{array}$ & $2(25)$ & $5(62.5)$ & $1(12.5)$ \\
\hline Prolactin $(\mathrm{n}=14, \mathrm{ng} / \mathrm{ml}$ & $4.1-18.4$ & $0(0)$ & $8(57.1)$ & $6(42.9)$ \\
\hline
\end{tabular}

TSH, thyroid-stimulating hormone; fT4, free thyroxine; ACTH, adrenocorticotropic hormone; FSH, follicle-stimulating hormone; LH, luteinizing hormone; $\mathrm{GH}$, growth hormone.

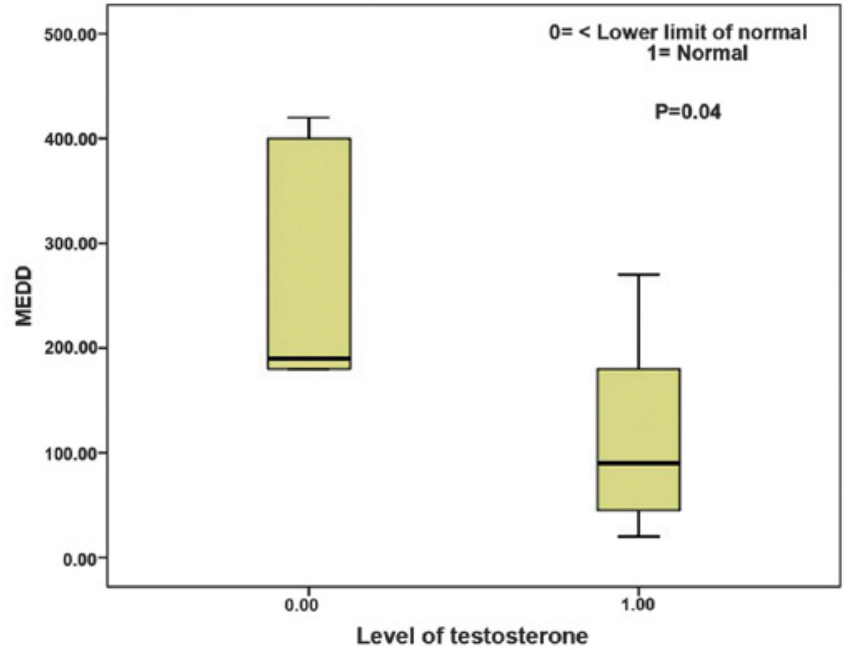

Figure 1. MEDD scores and association with testosterone levels. MEDD, morphine equivalent daily dose.

\section{Discussion}

Opioids induce a wide spectrum of endocrinopathies, and hypogonadism is the most well-documented endocrinopathic adverse effect of opioid usage $(1,2)$. Although the effects of opioids on LH and sex hormone release have yet to be fully understood, opioids may alter the sex hormone-hypothalamic feedback process (3). Opioids may also interfere with the pituitary release of LH and FSH (3). Lastly, opioids may have direct negative effects on the testes, resulting in decreased testosterone secretion and decreased testicular interstitial fluid (8).

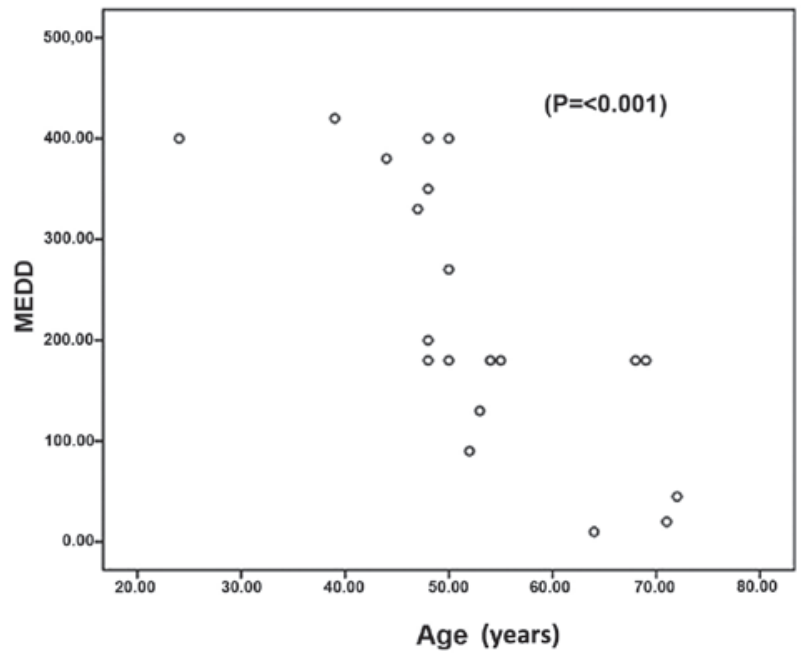

Figure 2. Opioid requirement is affected by age. MEDD, morphine equivalent daily dose.

The results of the present study demonstrated that opioid therapy in patients with cancer may inhibit gonadal function and cause hyperprolactinemia. It has previously been reported that testosterone levels decrease as the MEDD increases $(2,8)$, and the results of the present study are concordant with this. No statistically significant correlation was identified between opioid dosage and TSH, GH, FSH or LH levels. However, prolactin hormone levels increased with MEDD.

Opioid-induced suppression of the HPA axis is not a common differential diagnosis and may be misdiagnosed in clinical settings. The exact mechanism underlying the 
association of opioids with hypocortisolism is unknown. There are rare case reports of adrenal insufficiency secondary to chronic opioid usage $(10,11)$. Weakness and fatigue are symptoms frequently observed in patients with cancer. These symptoms may be attributed to the underlying malign disease, but may also be associated with adrenocortical insufficiency in the case of chronic high-dose opioid usage. The results of the present study demonstrated markedly low ACTH and cortisol levels in patients with cancer-associated pain, although the association between opioid chronic usage and low ACTH and cortisol levels was not found to be statistically significant.

The results also showed that opioid analgesic requirement increases with age. Further studies are required in order to clarify the mechanisms underlying these effects.

The signs and symptoms of hypogonadism range from loss of libido and depression to fatigue and osteoporosis. These symptoms can also be seen in patients with chronic cancer but without any hypogonadism.

In conclusion, it is recommended that patients with cancer should be screened for sex hormone deficiency prior to the initiation of opioid treatment, and should be followed-up regularly for hypogonadism during opioid treatment. In addition, further studies are required in order to further clarify the association between hypocortisolism, decreased GH and TSH levels, and opioid usage.

\section{Acknowledgements}

The abstract was presented at the 39th ESMO Congress Sep 26-30, 2014 in Madrid, Spain and published as abstract no. 1525P in Ann Oncol 25 (Suppl 4): 2014.

\section{References}

1. Dev R, Hui D, Dalal S, Nooruddin ZI, Yennurajalingam S, Del Fabbro E and Bruera E: Association between serum cortisol and testestorone levels, opioid therapy and symptom distress in patients with advanced cancer. J Pain Symptom Manage 41: 788-795, 2011

2. Rajagopal A, Vassilopoulou-Sellin R, Palmer JL, Kaur G and Bruera E: Symptomatic hypogonadism in male survivors of cancer with chronic exposure to opioids. Cancer 100: 851-858, 2004.

3. Colameco S and Coren JS: Opioid-induced endocrinopathy. J Am Osteopath Assoc 109: 20-25, 2009.

4. Abs R, Verhelst J, Maeyaert J, Van Buyten JP, Opsomer F, Adriaensen H, Verlooy J, Van Havenbergh T, Smet M and Van Acker K: Endocrine consequences of long-term intratecal administration of opioids. J Clin Endocrinol Metab 85: 2215-2222, 2000.

5. Lee C, Ludwig S and Duerksen DR: Low-serum cortisol associated with opioid use: Case report and review of the literature. Endocrinologist 12: 5-8, 2002.

6. Vuong C, Van Uum SH, O'Dell LE, Lutfy K and Friedman TC: The effects of opioids and opioid analogs on animal and human endocrine systems. Endocr Rev 31: 98-132, 2010.

7. Ducat E, Ray B, Bart G, Umemura Y, Varon J, Ho A and Kreek MJ: Mu-opioid receptor A118G polymorphism in healthy volunteers affects hypothalamic-pituitary-adrenal axis adrenocorticotropic hormone stress response to metyrapone. Addict Biol 18: 325-331, 2013.

8. Adams ML, Sewing B, Forman JB, Meyer ER and Cicero TJ: Opioid-induced suppression of rat testicular function. J Pharmacol Exp Ther 266: 323-328, 1993

9. Cepeda MS, Etropolski M, Weinstein R, Fife D, Boston R and Matcho A: Dose patterns in commercially insured subjects chronically exposed to opioids: A large cohort study in the United States. BMC Palliat Care 9: 14, 2010.

10. Oltmanns KM, Fehm HL and Peters A: Chronic fentanyl application induces adrenocortical insufficiency. J Intern Med 257: 478-480, 2005

11. Schimke KE, Greminger $P$ and Brändle M: Secondary adrenal insufficiency due to opiate therapy - another differential diagnosis worth consideration. Exp Clin Endocrinol Diabetes 117: 649-651, 2009. 